\title{
Seasonal cues to food scarcity and calorie cravings: Winter cues elicit preferences for energy-dense foods
}

Michał Folwarczny ${ }^{1}$, Tobias Otterbring ${ }^{2}$, Valdimar Sigurdsson ${ }^{1}$, and Agata Gasiorowska ${ }^{3}$

${ }^{1}$ Department of Business Administration, Reykjavik University

${ }^{2}$ Department of Management, University of Agder \& Institute of Retail Economics

${ }^{3}$ Faculty of Psychology in Wroclaw, SWPS University of Social Sciences and Humanities

\section{Author Note}

Michał Folwarczny (iD) https://orcid.org/0000-0002-1686-4933

Correspondence concerning this article should be addressed to Michał Folwarczny, Department of Business Administration, Reykjavik University, Menntavegur 1, 101 Reykjavik, Iceland. E-mail: michalf@tuta.io

This project was funded by the Icelandic Research Fund (Doctoral Student Grant to Michał Folwarczny number 206880-051).

MF developed the research concept. All authors contributed to research design. MF performed research and data analysis. MF drafted the manuscript. All authors provided critical revisions and approved the final version of the manuscript. 


\begin{abstract}
Winter cues signal a scarcity of food. Birds and mammals respond to such environmental cues by consuming more energy. They convert this surplus into body fat that serves as a buffer against impending food shortages. Similarly, humans exhibit higher obesity rates among food-insecure populations. However, to date, it has been unclear whether winter cues qualitatively affect consumers' food preferences. Results from five studies $(N=865)$, with one of them preregistered, show that watching videos depicting winter cues elicits thoughts about energy-dense foods and survival. Winter cues elicit higher preferences for energy-dense than low-calorie foods, with this effect likely being different for women and men. A meta-analysis corroborate this conclusion. Accordingly, our results support the evolutionary account postulating that humans have developed sex-specific responses to perceivable cues to food scarcity. As a result, winter cues induce people to favor products they deem higher in calories. Given the importance of limiting energy-dense food consumption for addressing environmental and public health issues, policymakers and marketers should be aware of this phenomenon when designing public communication campaigns.
\end{abstract}

Keywords: winter cues, food scarcity, food shortages, the insurance hypothesis, food preferences 


\section{Seasonal cues to food scarcity and calorie cravings: Winter cues elicit preferences for energy-dense foods}

\section{Introduction}

Numerous mammals and birds consume excessive amounts of energy to build fat reserves before the winter and limit their physical activity over these dark and cold months (Blix, 2016). Humans appear to have developed similar mechanisms that protect them against periods of lower food availability in the environment (Humphries et al., 2017; Neel, 1962; Prentice et al., 2005). Indeed, according to Gallup, Americans consume fewer low-calorie products and exercise less in the winter than in warmer seasons, thus leading to fat gain (Mendes, 2011). Eating contexts and environmental cues -including those elicited

in virtual environments - influence food choices and preferences (e.g., Ammann et al., 2020; Cardello et al., 2000; Cherulnik, 1991; Jaeger \& Rose, 2008; King et al., 2004; Pennanen et al., 2020). Their role in developing overweight and obesity has been acknowledged (Wells et al., 2007). Still, no studies have investigated if exposing people to environmental cues to winter facilitates energy-dense (vs. low-calorie) food preferences. This paper tests this possibility and conveys implications for public health, sustainability research, and policy-making because avoiding animal-source, energy-dense food is vital for addressing climate change and public health issues (Willett et al., 2019; Wynes \& Nicholas, 2017).

\section{Winter as a food scarcity cue}

Winter is an environmental cue to the reduced food supply. In some regions of the world, cold temperatures, coupled with a lack of sunlight, stop most vegetation forms, leading to a lack of food resources across species inhabiting these lands (Blix, 2016). Such food scarcity forces animals to migrate to other places or adjust their foraging strategies (Humphries et al., 2017). Humans, too, have experienced food scarcity resulting from cold periods. The Little Ice Age - climate cooling between 1300 and 1850 resulted in numerous extreme food shortages. For instance, the Great Famine killed tens of thousands of people between 1315 and 1319, whereas the Year Without a Summer led to crop failures and 
pervasive famine worldwide in 1816 (Fagan, 2001). In fact, our ancestors rarely enjoyed easy access to food resources. Instead, they wandered between food availability and food scarcity, which led them to develop mechanisms protecting against the latter periods (Rozin, 1996). An example of how such adaptations operate is the case of the Dutch Hunger Winter that happened in 1944-1945 in the occupied Netherlands, which resulted in extreme malnutrition at a national level. Babies exposed to malnutrition in early gestation due to this famine were more likely to be obese in later life (Schulz, 2010). In sum, throughout evolutionary history, cues to winter have signaled periods of lower food availability among humans and other species. Thus, it is reasonable to assume that humans have developed food intake mechanisms protecting them against food scarcity.

\section{Adaptations to winter-induced food scarcity among humans and other species}

Across the globe, plants and animals possess adaptations that allow them to endure seasonal temperature changes (Humphries et al., 2017). For instance, Arctic and Antarctic mammals and birds prepare for food scarcity during winter by depositing large amounts of fat during autumn and developing a considerable amount of brown adipose tissue vital for nonshivering thermogenesis (Blix, 2016). Adult humans, likewise, develop brown adipose tissue faster in the winter than in the summer, and its growth depends rather on sunlight than on temperature, with this effect being more pronounced among women than men (Au-Yong et al., 2009). Mirroring other species' behaviors, people consume more calories in the colder months, but also report being hungrier after meals (De Castro, 1991). In the fall, humans' diet composition changes - they consume more fat, which likely explains their $0.5 \mathrm{~kg}$ higher weight on average in the winter than in the summer (Ma et al., 2006). These calorie cravings may be partially due to increased heat production in the winter - when humans are exposed to cold air-than in the summer (Van Ooijen et al., 2004).

\section{Evolutionary roots of human food preferences: The insurance hypothesis}

Thorough evolutionary history, humans have developed mechanisms guiding their food choices to promote survival. For instance, people seem particularly prone to detect 
contaminated foods, which elicit strong disgust reactions (Egolf et al., 2018; Siegrist et al., 2020). Likewise, the human body reacts to too low protein consumption by increasing fat and carbohydrates intake (Simpson \& Raubenheimer, 2005). The similarities in relative food preferences across cultures support the evolutionary account explaining food preferences in modern societies. For example, the Hadza foragers living in Tanzania show a bias toward energy-dense foods akin to the typically preferred foods in developed countries (Berbesque \& Marlowe, 2009).

According to the insurance hypothesis (Nettle et al., 2017), humans and other vertebrates have developed mechanisms protecting them against periods of food unavailability that work through an increased energy consumption above the maintenance level, thus favoring fat storage. A meta-analysis of epidemiological studies provides evidence for this evolutionary account and suggests that food insecurity is positively related to the prevalence of overweight and obesity in developed countries; however, this relationship is found only among women (Nettle et al., 2017). These differences could have arisen due to past, sex-specific roles in the society wherein men were primarily concerned with hunting and fighting. In contrast, women were preoccupied with foraging and offspring activities (Silverman \& Eals, 1992). Thus, given the importance of mobility, an excessive bodyweight would have had more devastating consequences for men than women. Such a weight-management pattern is observed among small birds that maintain less fat reserves in the winter whenever there are many predators in their environments; however, when predators are absent, these birds increase fat reserves, thereby boosting surviving rates during this period (Gosler et al., 1995).

Although the literature implies that people experiencing food scarcity eat more (hence their weight gain), it remains unclear whether they make qualitatively different food choices and whether the mere exposure to winter cues is sufficient to alter their food preferences. A few studies indicate that people's fat intake increases in the fall-as opposed to the intake of other macronutrients (Ma et al., 2006); thus, they likely do not merely eat 
more when preparing for colder months; instead, their food preferences may have shifted.

Whereas winter cues signal lower food availability in nature, economic and technological advancements have provided a stable and sufficient food supply, at least in developed countries. Therefore, people living in these countries should be insensitive to such cues, as a threat of famine is unlikely in their case. However, such relative prosperity is a new phenomenon in human history. Yet, our cognitive system has evolved slowly, through thousands of years. As such, it is adjusted to cope with immediate challenges found in ancestral rather than current environments (Tooby \& Cosmides, 1990). Consequently, people often fail to distinguish between actual threats and cues associated with threats found in the distant past. For example, although snakes and spiders pose little danger in modern cities, people tend to be afraid of them more than cars and other more recent phenomena (cf. Griskevicius et al., 2012; Ornstein \& Ehrlich, 2000). Therefore, cues to food scarcity may activate mechanisms responsible for coping with past challenges, causing a mismatch between evolutionarily old mechanisms and our current needs (Li et al., 2018).

This account has received recent empirical support (Folwarczny et al., 2021). The authors exposed participants - primarily from Denmark and the United States - to videos depicting climate change-induced food scarcity (e.g., famine, drought, crop failures) happening in distant parts of the world, such as southern Africa. Crucially, this scarcity was depicted as distant in time, with the video clips mentioning future rather than current threats. Although the videos displayed food scarcity not threatening participants directly, their food preferences shifted toward higher-calorie foods, and this effect was most pronounced among women (Folwarczny et al., 2021).

\section{Research aims}

In the present research, we explore the possibility that exposing people to winter (vs. summer) cues makes them more inclined to think about energy-dense foods, survival, and scarcity, but not about low-calorie products. We also tested if winter cues affect people's food preferences as a function of their calorie content and whether this effect was 
sex-specific.

Drawing from the insurance hypothesis (Nettle et al., 2017), we contend that winter cues that used to signal food scarcity in the past may activate the same food acquiring mechanisms among people as actual food scarcity does. Consequently, consumers' preferences may shift under such circumstances, with a stronger emphasis directed toward energy-dense foods that increase overall energy intake above maintenance levels.

The energetic density of various food items is usually expressed in calories. The literature suggests that information about the calorie content plays a vital role in food choices, reducing overall calorie intake (Wisdom et al., 2010). However, on average, only women lower their calorie intake when they know the calorie content of dishes they consume (Gerend, 2009). Challenging this earlier literature, we hypothesize that exposure to winter cues will trigger preferences toward higher-calorie foods, with this effect being more pronounced among women than men (cf. Nettle et al., 2017).

\section{General method and overview of studies}

We conducted a pretest to ensure that both experimental videos yielded similar affective responses (see Supplementary Online Materials for details). The results of Studies 1a and $1 \mathrm{~b}$ confirmed that our experimental manipulation was successful. Here, we investigated whether exposure to winter cues makes people think about energy-dense (vs. low-calorie) foods, scarcity, and survival. In Studies 2a-2c, we tested our central hypotheses and demonstrated that exposing participants to videos depicting winter cues increases their preferences toward energy-dense foods, with this effect being different for women and men. We supported the key findings with a meta-analysis performed across Studies 2a-2c and the three studies by Folwarczny et al. (2021); for a similar procedure, see Orquin et al. (2020).

Data, materials, PsyToolkit scripts (Stoet, 2010, 2017), and analysis code are

publicly available under this project's Open Science Framework (OSF) webpage. Studies 2a and $2 \mathrm{~b}$ followed the same analytical protocol as the preregistered Study 2c; the preregistration can be accessed through this link. Regression coefficients and standard 
errors were multiplied by 100 across Studies 2a-2c when we report them for kilocalorie estimates. We did so for readability purposes and to make coefficients more meaningful - people measure hundreds of kilocalories rather than every single kilocalorie in complex meals.

This project adheres to ethical guidelines specified in the APA Code of Conduct and has been approved by the Ethics Committee for Human Research of [blinded for review purpose]. We recruited all participants through Prolific.co. To ensure high data quality, we recruited different participants for each experiment whose submission acceptance rate was $99 \%$ or higher.

\section{Study 1a}

Study 1a was conducted to test whether our experimental manipulation (winter cues vs. summer cues) influences people's propensity to think about energy-dense foods and scarcity-related concepts. Here, we used the word fragment completion task. This procedure is widely applied in experimental research and can be used to investigate if primes increase accessibility to thoughts related to them (Gasiorowska et al., 2018; Nelson et al., 1989; Roediger et al., 1992; Tulving et al., 1982).

\section{Method}

Participants. We recruited 106 U.S. participants on Prolific Academic (48 females, $M_{\text {age }}=36.37$ years, $S D=13.26$ ) to take part in a study in exchange for $£ 0.50$. The word fragment completion tasks that we employ in Studies 1a-1b yield middle-to-large effect sizes (e.g., Gasiorowska et al., 2018). We performed a stochastic power simulation in $\mathrm{R}$ (Bolker, 2007), which revealed that this sample size provided .90 power to detect a significant effect of this magnitude, that is, equal to Cohen's $d=0.65$. We used Prolific's prescreening features to ensure that only people without dietary restrictions (e.g., veganism, gluten-free diets) participated in the study.

Procedure. After accepting an informed consent form, participants were randomly assigned to one of the two conditions. They watched either a video showing a 
forest walk in the winter or in the summer.

Next, they performed the word fragment completion task. Participants had to complete 15 different word fragments. For example, the word S P _ S E could be completed as sparse or spouse. Seven of these word fragments could be completed in a way related to scarcity (scarce, poor, sparse, restrict, short, scanty, and skimpy). Four words could be completed in a way related to energy-dense foods (burger, steak, fries, and taco), and the remaining four words (sponge, door, change, phone) served as filler tasks to prevent participants from guessing the hypothesis.

We used conditional statements in $\mathrm{R}$ to find whether participants created words of a correct length (they could complete a word fragment in two ways: by typing the whole word or typing missing letters only; hence, there were two valid alternatives), and the "grepl" function served to find whether participants answered questions according to the predefined key (e.g., "arc" in the word "scarce," shown as S C E). We calculated (1) the number of words related to scarcity, (2) the number of words related to energy-dense foods, and (3) the overall number of correct words provided by participants. The word was counted as correct when it was found in one of the several online dictionaries used for predefining correct responses, whereas it was not counted when a participant failed to respond, created words of incorrect length, or created a word that was not found in online dictionaries. We calculated a proportion of words related to scarcity and energy-dense foods, respectively, by dividing the number of words related to scarcity and energy-dense foods by the total number of correct words and used them as dependent variables. The study concluded by participants providing demographic details.

\section{Results and discussion}

Scarcity-related words. An independent samples $t$-test on the proportion of words related to scarcity found no difference between conditions $\left(M_{\text {winter }}=.17, S D=.14\right.$; $\left.M_{\text {summer }}=.17, S D=.13\right), t(104)=0.08, p=.933, d=0.02$. 
Words related to energy-dense foods. A similar analysis performed on the proportion of words denoting energy-dense foods revealed that participants who watched a video depicting winter (vs. summer) cues created more words denoting energy-dense foods $\left(M_{\text {winter }}=.25, S D=.16 ; M_{\text {summer }}=.16, S D=.12\right), t(104)=-3.32, p=.001, d=0.65$.

Discussion. Findings from Study 1a suggest that the video depicting winter cues made participants think about energy-dense foods to a more considerable extent than the video depicting summer cues. However, neither video prompted participants to think more about scarcity.

\section{Study $1 b$}

The results from Study 1a revealed that participants viewing winter forest walks were more inclined to think about energy-dense foods than participants viewing summer forest walks, whereas our experimental manipulation did not influence the accessibility of scarcity-related concepts. In Study 1b, we tested whether winter (vs. summer) cues may also activate survival-related concepts while simultaneously examining whether our experimental manipulation affects the accessibility of thoughts about low-calorie foods.

\section{Method}

Participants. We recruited 105 U.S. participants on Prolific Academic (48 females, $M_{\text {age }}=35.16$ years, $\left.S D=11.43\right)$ to take part in a study in exchange for $£ 0.50$. Following the approach used in Study 1a, this sample size should be sufficient to detect the effect of interest. We have applied the same prescreening criteria as described in Study 1a.

Procedure. After accepting an informed consent form, participants were randomly assigned to one of the two conditions. They watched either a video showing a forest walk in the winter or in the summer.

Similar to Study 1a, participants then completed 15 different word fragments. Seven of these word fragments could be completed in a way related to survival (survive, endure, resist, persist, sustain, withstand, fight). Four words could be completed in a way related to low-calorie foods (salad, apple, milk, peach), and the remaining four words (sponge, door, 
change, phone) served as filler tasks to prevent participants from guessing the hypothesis. We applied the same procedure to calculate dependent variables and detect keyed responses as in Study 1a. The study concluded by participants providing demographic details.

\section{Results and discussion}

Survival-related words. An independent samples $t$-test on the proportion of words related to survival found that participants who watched a video showing winter (vs. summer) cues created more words related to survival $\left(M_{\text {winter }}=.26, S D=.14 ; M_{\text {summer }}=\right.$ $.17, S D=.13), t(103)=-3.22, p=.002, d=0.65$.

Words related to low-calorie foods. Aa similar analysis performed on the proportion of words denoting low-calorie foods revealed no significant difference between conditions $\left(M_{\text {winter }}=.18, S D=.12 ; M_{\text {summer }}=.20, S D=.13\right), t(103)=0.58, p=.566, d$ $=0.18$.

Discussion. Findings from Study 1b indicate that participants exposed to winter cues have higher accessibility to thoughts related to survival. However, they do not think more about low-calorie foods under such circumstances. Combined with the results from Study 1a, which found that watching winter cues made people think more about energy-dense foods, it is plausible that people link these foods to survival in harsh winter environments.

\section{Study 2a}

We conducted Study 2a to estimate the desired sample size before commencing the preregistration (Study 2c). We hypothesized that (1) exposing participants to winter (vs. summer) cues would increase their preferences toward energy-dense foods, and (2) this effect will be more pronounced among women than men.

\section{Method}

Participants. We recruited 119 U.S. participants on Prolific Academic (59 females, $M_{\text {age }}=36.40$ years, $S D=13.74$ ) to take part in a study in exchange for $£ 0.64$. 
Procedure. After accepting an informed consent form, participants were randomly assigned to one of the two conditions. They watched either a video showing a forest walk in the winter or in the summer.

After watching their given video, they estimated the caloric content and stated their preferences for 30 foods. We used food images from Folwarczny et al. (2021). This set of 30 simple foods and complex dishes has been pretested on certified nutritionists and athletes who daily measure the caloric content of foods. The set covers a broad spectrum in calorie estimates $\left(M_{\text {calories }}=367, S D=122\right.$, range $\left.=166-711\right)$ and has been applied in experimental research (Folwarczny et al., 2021). To evaluate the calorie content of foods ("How many calories does this food contain? [the serving you see]"), participants used a sliding scale ranging certified nutritionists' estimation of the calorie content of foods when creating this response format. Participants answered questions regarding their preferences toward foods ("Would you eat this food now?") on a sliding scale ranging from -1 = Definitely not to $1=$ Definitely yes, with .01 point intervals. The order of these two tasks (estimating calories and stating preferences) was randomized. Likewise, the order of the 30 food images within each task was randomized. The study concluded by participants providing demographic details.

\section{Results and discussion}

Primary hypothesis tests. Due to the nested data structure, we performed a mixed-effects analysis of the relationship between the two independent variables (treated as fixed effects; calorie estimates, and experimental condition) with interactions between them and the dependent variable (food preferences) using the "lme4" package for $\mathrm{R}$ (Bates et al., 2015). As random effects, we used intercepts for participants and foods. The visual inspection of residual plots suggested no apparent deviations from homoscedasticity or normality. We estimated significance with Satterthwaite's method applied by the "lmerTest" package for R (Kuznetsova et al., 2017).

This analyses revealed no main effects of experimental condition $(b=-7.863, S E=$ 
$7.117, t=-1.10, p=.270)$ or calorie estimates $(b=0.010, S E=0.009, t=1.14, p=.254)$ on food preferences. However, we found a marginally significant interaction between condition and calorie estimates $(b=0.020, S E=0.011, t=1.89, p=.059)$. Further simple slope analysis found that the relation between calories estimate and food preference was non-significant for participants exposed to videos featuring summer cues $(b=0.010$, $S E=0.009, t=1.14, p=.254)$, but it was significant and positive for participants exposed to videos depicting winter cues $(b=0.030, S E=0.008, t=3.53, p<.001)$. This pattern of results suggests that participants who watched videos depicting winter cues showed a stronger preference toward energy-dense foods than toward foods low in energy, while their peers exposed to videos depicting summer cues preferred foods to the same extent, regardless of their calorie content (Figure 1).

Secondary hypothesis tests. We added participants' biological sex as a moderator to test the hypothesis about sex differences in responses to the experimental manipulation. The results from this model (see Supplementary Online Materials for details), along with comparisons shown in Figure 1, indicate that the interaction effect between condition and calorie estimates on food preferences was different for women compared to men $(b=0.065, S E=0.021, t=3.07, p=.002)$. Thus, we decomposed this three-way interaction by investigating the effects of calories, experimental manipulation, and their interaction on food preference separately for men and women. For men, we found a significant main effect of calories $(b=0.030, S E=0.012, t=2.54, p=.011)$, but the interaction between condition and calorie estimates was non-significant $(b=-0.011, S E=$ 0.014, $t=-0.77, p=.443)$. For women, however, in line with our predictions, we found a significant interaction between condition and calorie estimates $(b=0.053, S E=0.016, t=$ $3.26, p=.001)$. We performed a simple slope analysis separately for both experimental conditions to further quantify this interaction. For women exposed to winter cues, the relation between calories estimate and food preferences was significant $(b=0.038, S E=$ 0.014, $t=2.80, p=.005)$, but for women exposed to summer cues this relationship was 
non-significant $(b=-0.015, S E=0.013, t=-1.13, p=.259)$. These results indicate that women watching videos depicting winter cues show a stronger preference toward energy-dense foods than toward low-calorie foods, but women watching videos featuring summer cues do not exhibit this response pattern.

Discussion. Results from Study 2a provide preliminary evidence for both our hypotheses. We found people exposed to winter cues, but not summer cues, to exhibit a stronger preference toward energy-dense foods than toward low-calorie foods. Furthermore, this effect was different between men and women. Whereas men preferred foods they deemed higher in calories, regardless of whether they were exposed to winter or summer cues, women showed a "craving for calories" only after exposure to winter cues.

\section{Study $2 b$}

The results from Study 2a provided initial evidence for our theorizing. However, based on these findings, we cannot rule out that the effects observed in Study 2a emerged as a function of summer rather than winter cues. Therefore, we conducted Study $2 \mathrm{~b}$ with a third condition, where participants did not watch any video before evaluating the foods. We hypothesized that exposing participants to summer cues would not alter their food preferences compared to participants who were not exposed to any visual stimuli. In contrast, exposing participants to winter cues should increase their preferences toward higher-calorie foods.

\section{Method}

Participants. We recruited 120 U.S. participants on Prolific Academic (74 females, $M_{\text {age }}=34.52$ years, $S D=11.54$ ) to take part in a study in exchange for $£ 0.64$.

Procedure. After accepting an informed consent form, participants were randomly assigned to one of the three conditions. They watched a video showing a forest walk in the winter, in the summer, or no video at all. The remaining procedure was the same as that of Study 2a. 


\section{Results and discussion}

Primary hypothesis tests. Again, we performed a mixed-effects analysis of the relationship between the two independent variables: calorie estimates and experimental condition (watching a summer forest walk, winter forest walk, or no video) with interactions between them and the dependent variable-food preferences. As random effects, we used intercepts for participants and foods. The visual inspection of residual plots suggested no apparent deviations from homoscedasticity or normality.

As a reference condition, we used a group that was not exposed to any video. The analysis indicated no main effect of calorie estimates $(b=0.008, S E=0.009, t=0.96, p=$ $.339)$. We found no main effect of the summer video $(b=-0.512, S E=8.575, t=-0.06, p$ $=.952)$, but a significant main effect of the winter video $(b=-23.847, S E=9.481, t=$ $-2.52, p=.012$ ), suggesting that this video may decrease food preferences compared to not watching any video. The interaction between condition and calorie estimates was non-significant for participants exposed to the video showing summer cues $(b=-0.010, S E$ $=0.011, t=-0.91, p=.364)$, but significant for participants exposed to the video showing winter cues $(b=0.037, S E=0.013, t=2.94, p=.003)$. To further understand the nature of this interaction, we performed a simple slope analysis for each experimental condition. For participants, who did not watch any video $(b=0.008, S E=0.009, t=0.96, p=.339)$, and their counterparts who watched the video depicting summer cues $(b=-0.002, S E=$ 0.009, $t=-0.18, p=.856)$, the slope of calories was non-significant. However, this slope was positive and significant for participants exposed to the video showing winter cues $(b=$ 0.046, $S E=0.011, t=4.25, p<.001)$, suggesting their stronger preference toward energy-dense foods than toward low-calorie foods. Given no major differences in key measures between the conditions in which participants either watched a video depicting summer cues or these, who did not watch any video, we merged these two conditions to facilitate parsimonious analysis (cf. Griskevicius et al., 2009; Griskevicius et al., 2010).

Next, we conducted the same analysis as in Study 2a. The main effect of calories 
was non-significant $(b=0.003, S E=0.007, t=0.50, p=.620)$. We found a main effect of experimental condition $(b=-23.458, S E=8.397, t=-2.79, p=.006)$, implying that participants exposed to winter videos showed lower overall preferences toward foods than participants in the other conditions. Crucially, and mirroring the findings from Study 2a, we found a significant interaction between calorie estimates and condition $(b=0.042, S E$ $=0.011, t=3.72, p<.001)$. Hence, we performed a simple slope analysis across conditions. For participants who did not watch any video or who watched a video featuring summer cues, the slope of calories was non-significant $(b=0.003, S E=0.007, t=0.50, p$ $=.620)$, but it was significant for those exposed to winter cues $(b=0.046, S E=0.011, t$ $=4.25,<.001)$, thus replicating the results from Study $2 \mathrm{a}$ - participants exposed to winter cues showed a stronger preference toward energy-dense foods than toward low-calorie foods.

Secondary hypothesis tests. We added participants' biological sex as a moderator to test the hypothesis about sex differences in responses to the experimental manipulation. In contrast to the findings from Study 2a, the interactional effect between condition and calorie estimates on food preferences did not differ across sexes $(b=-0.002$, $S E=0.023, t=-0.10, p=.923)$.

Discussion. The results from Study $2 \mathrm{~b}$ provide more substantive evidence for the notion that winter cues rather than summer cues alter consumers' food preferences and their cravings for calories. Specifically, exposure to winter cues increased participants' preferences for energy-dense foods more than low-calorie foods. Simultaneously, this effect did not occur for participants exposed to summer cues or who were not exposed to any visual stimuli before indicating their food preferences. However, unlike Study 2a, we did not find this effect to vary between men and women.

\section{Study 2c}

The results from Study 2a confirmed both our hypotheses, and the findings from Study $2 \mathrm{~b}$ confirmed our primary but not secondary hypothesis. In Study 2c, we preregistered both these focal hypotheses in a well-powered final study, where we specified 
our design and data analysis plan.

\section{Method}

Participants. Based on the observed power of Study 2a, as computed through the "simr" package for R (Green \& MacLeod, 2016), we plotted a power curve to estimate the number of participants needed to achieve .95 power to detect the significant interaction between condition and calorie estimates on food preferences. This procedure suggested that 420 participants were needed to achieve .95 power to detect the effect of interest. Thus, we recruited 420 U.S. participants on Prolific Academic to take part in the study in exchange for $£ 0.75$, of whom 415 completed tasks and were included in the analysis (204 females, $M_{\text {age }}=36.90$ years, $\left.S D=13.03\right)$.

Procedure. After accepting an informed consent form, participants were randomly assigned to one of the two conditions. They watched either a video showing a forest walk in the winter or in the summer. The remaining procedure mirrored that applied in Studies 2a-2b.

\section{Results and discussion}

Primary hypothesis tests. We followed the preregistered data analysis protocol, which is identical to that of Studies $2 \mathrm{a}-2 \mathrm{~b}$. We found no obvious deviations from homoscedasticity or normality. The analyses revealed a marginally significant main effect of condition $(b=7.027, S E=3.689, t=1.91, p=.057)$, implying that participants exposed to winter cues showed higher overall preferences toward foods. The main effect of calories was significant $(b=0.034, S E=0.004, t=8.00, p<.001)$, meaning that participants preferred foods they deemed higher in calories. However, in contrast to Studies $2 \mathrm{a}-2 \mathrm{~b}$, the results from Study 2c revealed no significant interaction between calorie estimates and condition $(b=-0.008, S E=0.005, t=-1.57, p=.117)$.

Secondary hypothesis tests. Next, in line with the preregistered protocol, we added participants' biological sex as a moderator to test the hypothesis about sex differences in responses to the experimental manipulation. The results from this model (see 
Supplementary Online Materials for details) indicated that the effect of condition and calorie estimates on food preferences was different for women compared to men $(b=0.035$, $S E=0.010, t=3.50, p<.001)$. Thus, we decomposed this interaction by investigating the effects of calories, experimental manipulation, and their interaction on food preference separately for men and women. For men, we found a significant main effect of calories $(b=$ 0.048, $S E=0.005, t=8.70, p<.001)$, indicating a higher preference for foods deemed as higher in calories. We also found a significant main effect of condition $(b=12.940, S E=$ 5.153, $t=2.51, p=.012)$, implying a higher overall preference toward foods among men exposed to winter than to summer cues. Finally, the interaction between experimental condition and calorie estimates was significant for men $(b=-0.024, S E=0.007, t=-3.66$, $p<.001)$. Further simple slope analysis revealed that men exposed to winter $(b=0.023$, $S E=0.006, t=4.24, p<.001)$ and summer $(b=0.048, S E=0.005, t=8.70, p<.001)$ cues showed a higher preference for energy-dense foods than low-calorie foods.

For women, we found a significant main effect of calorie estimates $(b=0.020, S E=$ 0.007, $t=3.01, p=.003)$, indicating a higher preference for foods deemed as higher in calories. However, the effect of condition was non-significant $(b=0.710, S E=5.265, t=$ $0.14, p=.893)$, as was the interaction between condition and calorie estimates $(b=0.009$, $S E=0.007, t=1.28, p=.202)$.

Discussion. Results from Study 2c did not support our primary hypothesis, as the interaction between experimental condition and calorie estimates did not emerge. As per our secondary hypothesis tests - we found the predicted three-way interaction. However, decomposing this interaction did not reveal the hypothesized pattern of results, as the interaction between calorie estimates and condition was non-significant for women, but it was significant for men. Still, for women, we observed a trend in the same direction as in Study 2a. To further test whether this trend could be interpreted in a meaningful way, we proceeded to the meta-analysis described below. 


\section{Figure 1}

Sex differences in responses to winter (vs. summer) cues across Studies 2a-2c
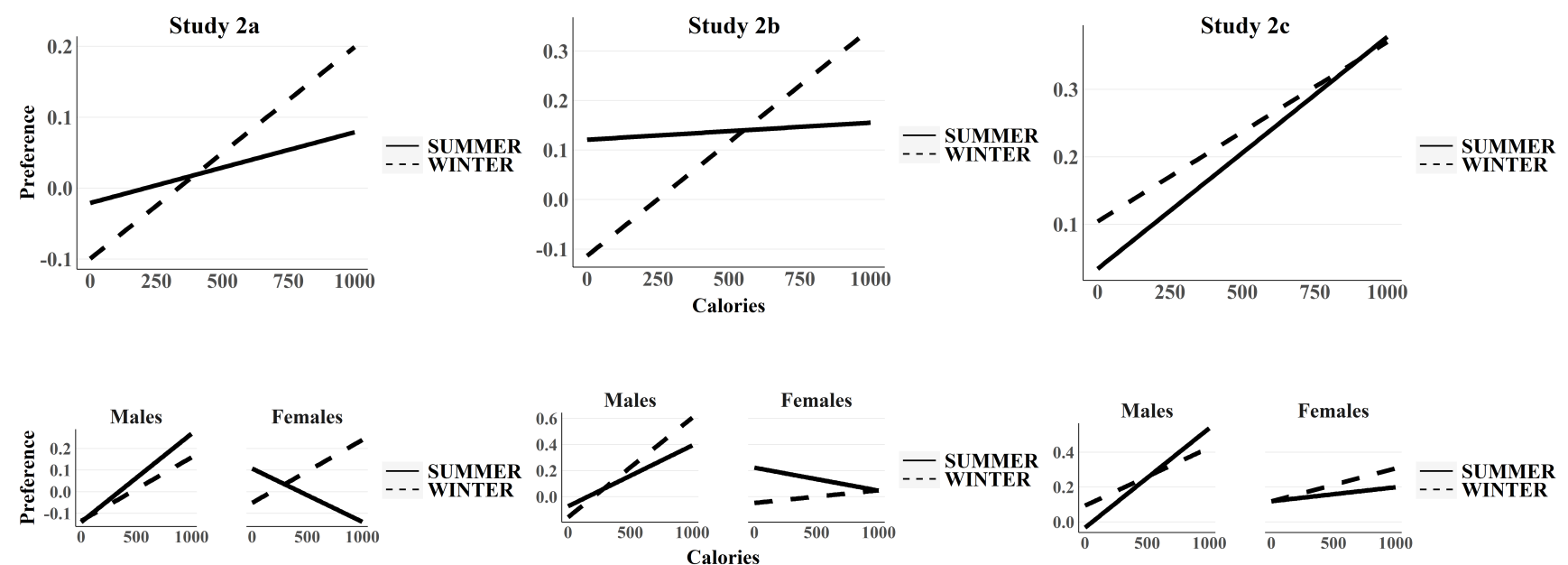

\section{Meta-analysis}

As not all of our studies supported the primary hypothesis, and the results of our secondary hypothesis tests yielded inconsistent findings across studies, we performed a meta-analysis with the "metafor" package for R (Viechtbauer, 2010). Our meta-analysis was based on the data from Studies 2a-2c together with the three studies by Folwarczny et al. (2021), which are conceptually similar to those reported herein in terms of procedures and measures (for details on this analytic approach, see Orquin et al., 2020).

Primary hypothesis results. We fit a random-effects model to test the primary hypothesis, that is, the interaction between calorie estimates and condition on food preferences. The results revealed high heterogeneity across studies, $I^{2}=75.80 \%, 95 \%$ CIs [56.25, 95.14] (Higgins et al., 2003), indicating that over half of the variation in the observed effects would remain if we removed sampling error (Borenstein et al., 2017). The estimated average effect was equal to $b=0.020, C I_{95}=[0.005,0.035]$. Thus, the null hypothesis can likely be rejected $(z=2.66, p=.008)$. Figure 2 shows a forest plot of this interaction effect across studies. 


\section{Figure 2}

Meta-analysis across studies of the condition $\times$ calorie estimates interaction effect

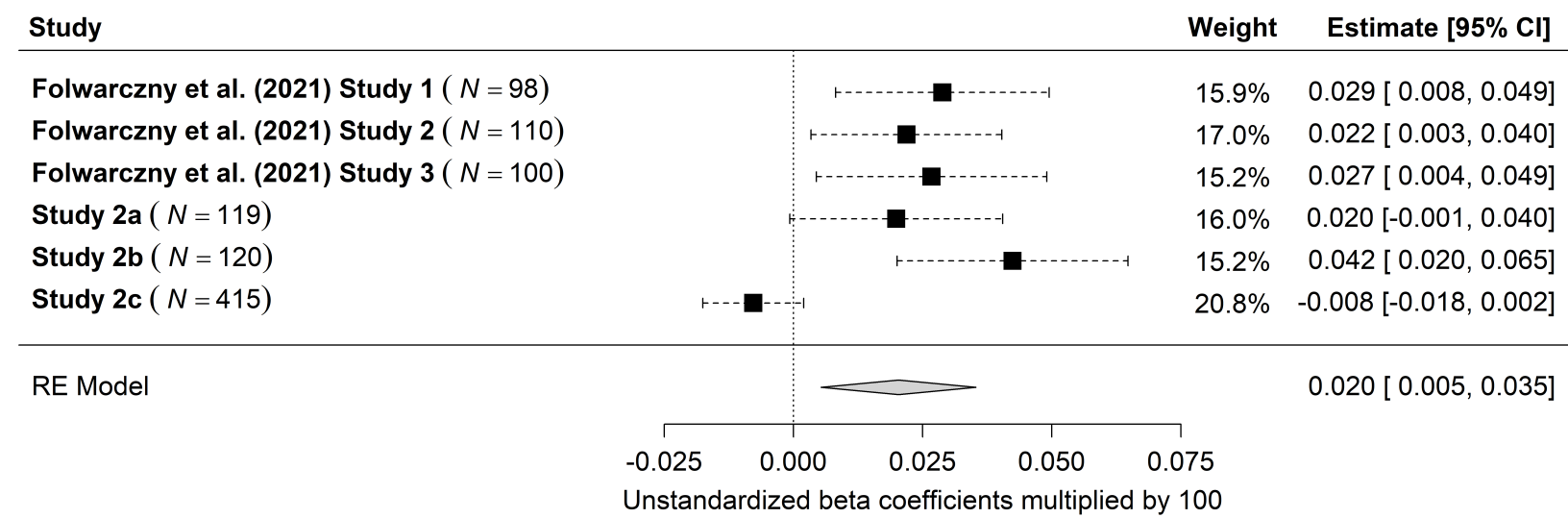

Secondary hypothesis results. We fit the same model to test the secondary hypothesis, that is, the interaction between calorie estimates, condition, and participant sex on food preferences. The results showed moderate-to-high heterogeneity of the effects across studies, $I^{2}=33.31 \%, 95 \%$ CIs [0.00, 91.61] (Higgins et al., 2003). However, the wide confidence intervals for the heterogeneity coefficients make it difficult to judge how much variation in the observed effects would remain if sampling error was removed (Borenstein et al., 2017). The estimated average effect was equal to $b=0.044, C I_{95}=[0.026,0.062]$. Thus, the null hypothesis can likely be rejected $(z=4.80, p<.001)$. Figure 3 shows a forest plot of this interaction effect across studies. 


\section{Figure 3}

Meta-analysis across studies of the condition $\times$ calorie estimates $\times$ participant sex interaction effect

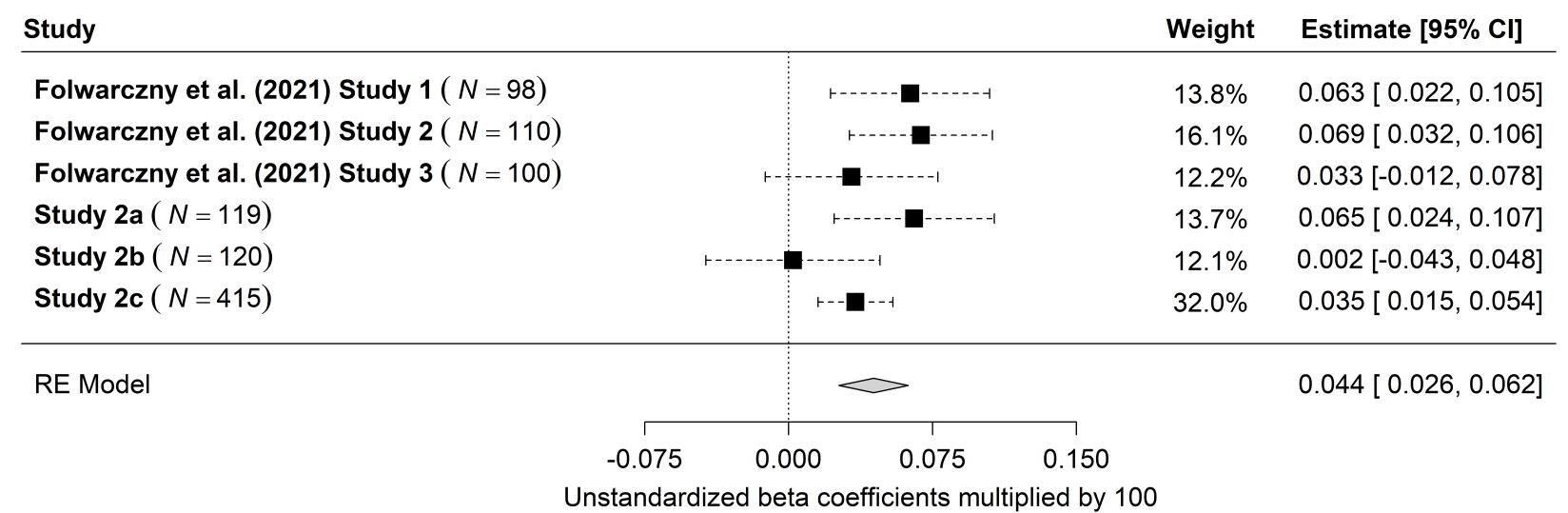

\section{General discussion}

Across five studies, we investigated if exposure to winter cues increases preferences toward energy-dense (vs. low-calorie) foods and whether this effect differs between men and women. Studies 1a-1b indicated that watching videos depicting winter (vs. summer) cues increased the accessibility of concepts linked to survival and energy-dense foods.

Winter cues, however, did not prompt people to think about low-calorie foods or scarcity to a larger extent than did summer cues. Studies 2a-2c jointly demonstrated that exposure to winter (vs. summer) cues elicited preferences for energy-dense (vs. low-calorie) foods. To further corroborate this conclusion and foster theory testing (McShane \& Böckenholt, 2017), we performed a meta-analysis across studies 2a-2c and related research, which documented an overall effect in the hypothesized direction, with winter cues increasing preferences for energy-dense (vs. low-calorie) foods, especially among women (vs. men). Nevertheless, the current findings are not conclusive and beg for additional experiments exploring these sex-specific effects. 
Our work extends the earlier research by Folwarczny et al. (2021). Whereas the authors used vivid and explicit food scarcity manipulations, we expose participants to subtle, unemotional food scarcity cues - videos showing a winter forest walk. Further, Folwarczny et al. (2021) used videos depicting obese individuals in their control condition. We purposely avoided videos showing humans in the control condition, as such stimuli also alter food preferences (Banovic \& Otterbring, 2021; Otterbring \& Shams, 2019). We further extend these earlier findings by showing that winter cues elicit thoughts associated with survival and energy-dense foods.

Our results provide empirical support for the insurance hypothesis (Nettle et al., 2017), postulating that humans and other vertebrates - through their evolutionary histories - have developed adaptations protecting them against periods of food scarcity, which facilitate energy consumption over the maintenance levels, thus contributing to weight gain. Indeed, food insecurity is linked to obesity in developed countries, but this effect is only found among women (Nettle et al., 2017). The current findings, too, indicate that exposing participants to winter cues - a proxy for food scarcity across species - directionally shifts food preferences toward energy-dense (vs. low-calorie) products mainly among women. To our knowledge, existing literature does not provide a well-supported account explaining these potential sex differences.

Over a third of adults worldwide are overweight and obese, and this public health issue becomes prevalent also among children (WHO, 2020). Excessive body weight - associated with numerous illnesses such as cardiovascular disease or diabetes mellitus - leads to millions of premature deaths globally each year and became an imminent problem in developing countries, despite being traditionally present exclusively in affluent societies (GBD 2015 Obesity Collaborators, 2017). Aside from health hazards, overweight and obesity causes a significant economic burden for individuals and public healthcare systems, as direct and indirect costs of excessive bodyweight over lifetime exceed $\$ 150,000$ per person (Hamilton et al., 2018). Consequently, the recent Lancet Commission called for 
urgent development of healthy and sustainable food systems (Willett et al., 2019). Whereas our findings do not provide insights into how environmental cues can be used to facilitate healthier eating habits, we provide evidence that winter cues and likely other similar cues to food scarcity may prompt consumers to prefer energy-dense foods over low-calorie alternatives, with the former being key culprits of excessive bodyweight (WHO, 2020).

Effective pro-environmental campaigns need to encourage choosing products and services that have the most negligible impact on the environment. However, such campaigns are often filled with cues that may attenuate their effectiveness. For example, an emotional campaign by Greenpeace International highlighting the issue of melting Arctic ice is filled with winter cues (Morgan, 2016). Because our studies found such cues to increase preferences toward energy-dense foods, which contribute to climate change (Wynes \& Nicholas, 2017), environmental organizations and policymakers may have to reevaluate their communication strategies. Likewise, marketing communication should be carefully designed, as it is often filled with winter cues, with the well-known Coca-Cola winter ads just constituting one salient example.

\section{Limitations and future research}

Winter has been associated with food scarcity for centuries among humans (Fagan, 2001). Thus, it is plausible that exposure to winter cues makes people think about scarcity in general. Interestingly, the current studies show that videos depicting winter cues trigger thoughts about survival and energy-dense foods, but not about scarcity. Future studies should further explore the underlying mechanisms of such diverging findings. Ideally, a psychometrically validated tool measuring anticipated food scarcity would provide evidence behind the proposed mechanisms activated as a response to exposure to winter cues. Such a tool is currently being developed by Folwarczny et al. (2020).

Notably, the current work focused solely on stated food preferences that may not be predictive of actual food choices; hence, our findings should be treated with caution until field studies employing behavioral measures have verified the replicability, generalizability, 
and real-world impact of our theorizing. Minimally, laboratory studies where participants can choose snacks with different calorie content as a part of their reward for taking part in a study may be commenced.

\section{Concluding remarks}

Five studies supported with a meta-analysis of related research jointly suggest that exposure to winter cues increases consumers' preferences for energy-dense foods. Due to the importance of limiting consumption of such foods to tackle environmental and public health issues, the present findings offer potential implications for environmental organizations and policymakers. 


\section{References}

Ammann, J., Hartmann, C., Peterhans, V., Ropelato, S., \& Siegrist, M. (2020). The relationship between disgust sensitivity and behaviour: A virtual reality study on food disgust. Food Quality and Preference, 80, 103833.

https://doi.org/10.1016/j.foodqual.2019.103833

Au-Yong, I. T., Thorn, N., Ganatra, R., Perkins, A. C., \& Symonds, M. E. (2009). Brown adipose tissue and seasonal variation in humans. Diabetes, 58(11), 2583-2587. https://doi.org/10.2337/db09-0833

Banovic, M., \& Otterbring, T. (2021). Athletic abs or big bellies: The impact of imagery, arousal levels, and health consciousness on consumers' attitudes towards plant-based protein products. Food Quality and Preference, 87, 104067. https://doi.org/10.1016/j.foodqual.2020.104067

Bates, D., Mächler, M., Bolker, B., \& Walker, S. (2015). Fitting linear mixed-effects models using lme4. Journal of Statistical Software, 6r(1), 1-48. https://doi.org/10.18637/jss.v067.i01

Berbesque, J. C., \& Marlowe, F. W. (2009). Sex differences in food preferences of hadza hunter-gatherers. Evolutionary Psychology, 7(4), 147470490900700409. https://doi.org/10.1177/147470490900700409

Blix, A. S. (2016). Adaptations to polar life in mammals and birds. Journal of Experimental Biology, 219(8), 1093-1105. https://doi.org/10.1242/jeb.120477

Bolker, B. (2007). Stochastic simulation and power analysis. http:/ / citeseerx.ist.psu.edu/viewdoc/summary?doi=10.1.1.720.8252

Borenstein, M., Higgins, J. P., Hedges, L. V., \& Rothstein, H. R. (2017). Basics of meta-analysis: I2 is not an absolute measure of heterogeneity. Research Synthesis Methods, 8(1), 5-18. https://doi.org/10.1002/jrsm.1230 
Cardello, A. V., Schutz, H., Snow, C., \& Lesher, L. (2000). Predictors of food acceptance, consumption and satisfaction in specific eating situations. Food Quality and Preference, 11 (3), 201-216. https://doi.org/10.1016/S0950-3293(99)00055-5

Cherulnik, P. D. (1991). Reading restaurant facades: Environmental inference in finding the right place to eat. Environment and Behavior, 23(2), 150-170. https://doi.org/10.1177/0013916591232002

De Castro, J. M. (1991). Seasonal rhythms of human nutrient intake and meal pattern. Physiology ES Behavior, 50(1), 243-248. https://doi.org/10.1016/0031-9384(91)90527-u

Egolf, A., Siegrist, M., \& Hartmann, C. (2018). How people's food disgust sensitivity shapes their eating and food behaviour. Appetite, 127, 28-36. https://doi.org/10.1016/j.appet.2018.04.014

Fagan, B. (2001). The Little Ice Age: how climate made history 1300-1850. Basic Books. Folwarczny, M., Christensen, J. D., Li, N. P., Sigurdsson, V., \& Otterbring, T. (2021). Crisis communication, anticipated food insecurity, and food preferences: Preregistered evidence of the insurance hypothesis. Food Quality and Preference, 91, 104213. https://doi.org/10.1016/j.foodqual.2021.104213

Folwarczny, M., Li, N. P., Sigurdsson, V., Tan, L. K., \& Otterbring, T. (2020). Development and psychometric evaluation of the Anticipated Food Scarcity Scale (AFSS). https://doi.org/10.31234/osf.io/gtx4n

Gasiorowska, A., Zaleskiewicz, T., \& Kesebir, P. (2018). Money as an existential anxiety buffer: Exposure to money prevents mortality reminders from leading to increased death thoughts. Journal of Experimental Social Psychology.

https://doi.org/10.1016/j.jesp.2018.09.004

GBD 2015 Obesity Collaborators. (2017). Health effects of overweight and obesity in 195 countries over 25 years. New England Journal of Medicine, 377(1), 13-27. https://doi.org/10.1056/NEJMoa1614362 
Gerend, M. A. (2009). Does calorie information promote lower calorie fast food choices among college students? Journal of Adolescent Health, 44(1), 84-86. https://doi.org/10.1016/j.jadohealth.2008.06.014

Gosler, A. G., Greenwood, J. J., \& Perrins, C. (1995). Predation risk and the cost of being fat. Nature, 377(6550), 621-623. https://doi.org/10.1038/377621a0

Green, P., \& MacLeod, C. J. (2016). SIMR: An R package for power analysis of generalized linear mixed models by simulation. Methods in Ecology and Evolution, 7(4), 493-498. https://doi.org/10.1111/2041-210X.12504

Griskevicius, V., Cantú, S. M., \& Van Vugt, M. (2012). The evolutionary bases for sustainable behavior: Implications for marketing, policy, and social entrepreneurship. Journal of Public Policy E Marketing, 31(1), 115-128. https://doi.org/10.1509/jppm.11.040

Griskevicius, V., Goldstein, N. J., Mortensen, C. R., Sundie, J. M., Cialdini, R. B., \& Kenrick, D. T. (2009). Fear and loving in Las Vegas: Evolution, emotion, and persuasion. Journal of Marketing Research, 46 (3), 384-395. https://doi.org/10.1509/jmkr.46.3.384

Griskevicius, V., Tybur, J. M., \& Van den Bergh, B. (2010). Going green to be seen: Status, reputation, and conspicuous conservation. Journal of Personality and Social Psychology, 98(3), 392-404. https://doi.org/10.1037/a0017346

Hamilton, D., Dee, A., \& Perry, I. (2018). The lifetime costs of overweight and obesity in childhood and adolescence: A systematic review. Obesity Reviews, 19(4), 452-463. https://doi.org/10.1111/obr.12649

Higgins, J. P., Thompson, S. G., Deeks, J. J., \& Altman, D. G. (2003). Measuring inconsistency in meta-analyses. BMJ, 327(7414), 557-560. https://doi.org/10.1136/bmj.327.7414.557

Humphries, M. M., Studd, E. K., Menzies, A. K., \& Boutin, S. (2017). To everything there is a season: Summer-to-winter food webs and the functional traits of keystone 
species. Integrative and Comparative Biology, 57(5), 961-976.

https://doi.org/10.1093/icb/icx119

Jaeger, S. R., \& Rose, J. M. (2008). Stated choice experimentation, contextual influences and food choice: A case study. Food Quality and Preference, 19(6), 539-564. https://doi.org/10.1016/j.foodqual.2008.02.005

King, S. C., Weber, A. J., Meiselman, H. L., \& Lv, N. (2004). The effect of meal situation, social interaction, physical environment and choice on food acceptability. Food Quality and Preference, 15(7-8), 645-653.

https://doi.org/10.1016/j.foodqual.2004.04.010

Kuznetsova, A., Brockhoff, P. B., Christensen, R. H., et al. (2017). lmerTest package: Tests in linear mixed effects models. Journal of Statistical Software, 82(13), 1-26. https://doi.org/10.18637/jss.v082.i13

Li, N. P., van Vugt, M., \& Colarelli, S. M. (2018). The evolutionary mismatch hypothesis: Implications for psychological science. Current Directions in Psychological Science, 27(1), 38-44. https://doi.org/10.1177/0963721417731378

Ma, Y., Olendzki, B. C., Li, W., Hafner, A. R., Chiriboga, D., Hebert, J. R., Campbell, M., Sarnie, M., \& Ockene, I. S. (2006). Seasonal variation in food intake, physical activity, and body weight in a predominantly overweight population. European Journal of Clinical Nutrition, 60(4), 519-528.

https://doi.org/10.1038/sj.ejcn.1602346

Macht, M. (2008). How emotions affect eating: A five-way model. Appetite, 50(1), 1-11. https://doi.org/10.1016/j.appet.2007.07.002

Marteau, T. M., \& Bekker, H. (1992). The development of a six-item short-form of the state scale of the Spielberger State - Trait Anxiety Inventory (STAI). British Journal of Clinical Psychology, 31 (3), 301-306.

https://doi.org/10.1111/j.2044-8260.1992.tb00997.x 
McShane, B. B., \& Böckenholt, U. (2017). Single-paper meta-analysis: Benefits for study summary, theory testing, and replicability. Journal of Consumer Research, 43(6), 1048-1063. https://doi.org/10.1093/jcr/ucw085

Mendes, E. (2011). U.S. health habits continue sharp winter decline. https: //news.gallup.com/poll/151424/health-habits-continue-steep-winter-decline.aspx

Morgan, J. (2016). The melting Arctic ice calls for protecting what I love. https://www.greenpeace.org/international/story/7028/the-melting-arctic-ice-callsfor-protecting-what-i-love/

Neel, J. V. (1962). Diabetes mellitus: A "thrifty" genotype rendered detrimental by "progress"? American Journal of Human Genetics, 14(4), 353-362.

Nelson, D. L., Keelean, P. D., \& Negrao, M. (1989). Word-fragment cuing: The lexical search hypothesis. Journal of Experimental Psychology: Learning, Memory, and Cognition, 15(3), 388-397. https://doi.org/10.1037/0278-7393.15.3.388

Nettle, D., Andrews, C., \& Bateson, M. (2017). Food insecurity as a driver of obesity in humans: The insurance hypothesis. Behavioral and Brain Sciences, 40. https://doi.org/10.1017/S0140525X16000947

Ornstein, R. E., \& Ehrlich, P. R. (2000). New world new mind: Moving toward conscious evolution. ISHK.

Orquin, J. L., Dalgaard, C. J., \& Lagerkvist, C. J. (2020). A meta-analytical and experimental examination of blood glucose effects on decision making under risk. Judgment and Decision Making, 15(6), 1024-1036.

Otterbring, T., \& Shams, P. (2019). Mirror, mirror, on the menu: Visual reminders of overweight stimulate healthier meal choices. Journal of Retailing and Consumer Services, 47, 177-183. https://doi.org/10.1016/j.jretconser.2018.11.019

Pennanen, K., Närväinen, J., Vanhatalo, S., Raisamo, R., \& Sozer, N. (2020). Effect of virtual eating environment on consumers' evaluations of healthy and unhealthy 
snacks. Food Quality and Preference, 82, 103871. https://doi.org/10.1016/j.foodqual.2020.103871

Prentice, A. M., Rayco-Solon, P., \& Moore, S. E. (2005). Insights from the developing world: Thrifty genotypes and thrifty phenotypes. Proceedings of the Nutrition Society, 64(2), 153-161. https://doi.org/10.1079/PNS2005421

Roediger, H. L., Weldon, M. S., Stadler, M. L., \& Riegler, G. L. (1992). Direct comparison of two implicit memory tests: Word fragment and word stem completion. Journal of Experimental Psychology: Learning, Memory, and Cognition, 18(6), 1251-1269. https://doi.org/10.1037//0278-7393.18.6.1251

Rozin, P. (1996). Towards a psychology of food and eating: From motivation to module to model to marker, morality, meaning, and metaphor. Current Directions in Psychological Science, 5(1), 18-24. https://doi.org/10.1111/1467-8721.ep10772690

Schulz, L. C. (2010). The Dutch Hunger Winter and the developmental origins of health and disease. Proceedings of the National Academy of Sciences, 107(39), 16757-16758. https://doi.org/10.1073/pnas.1012911107

Siegrist, M., Bearth, A., \& Hartmann, C. (2020). Food disgust sensitivity influences the perception of food hazards: Results from longitudinal and cross-cultural studies. Appetite, 153, 104742. https://doi.org/10.1016/j.appet.2020.104742

Silverman, I., \& Eals, M. (1992). Sex differences in spatial abilities: Evolutionary theory and data. In J. H. Barkow, L. Cosmides, \& J. Tooby (Eds.), The adapted mind: Evolutionary psychology and the generation of culture (pp. 533-549).

Simpson, S. J., \& Raubenheimer, D. (2005). Obesity: The protein leverage hypothesis. Obesity Reviews, 6(2), 133-142. https://doi.org/10.1111/j.1467-789X.2005.00178.x

Stoet, G. (2010). PsyToolkit: A software package for programming psychological experiments using linux. Behavior Research Methods, 42(4), 1096-1104. https://doi.org/10.3758/BRM.42.4.1096 
Stoet, G. (2017). PsyToolkit: A novel web-based method for running online questionnaires and reaction-time experiments. Teaching of Psychology, 44 (1), 24-31. https://doi.org/10.1177/0098628316677643

Tooby, J., \& Cosmides, L. (1990). The past explains the present: Emotional adaptations and the structure of ancestral environments. Ethology and Sociobiology, 11(4-5), 375-424. https://doi.org/10.1016/0162-3095(90)90017-Z

Tulving, E., Schacter, D. L., \& Stark, H. A. (1982). Priming effects in word-fragment completion are independent of recognition memory. Journal of Experimental Psychology: Learning, Memory, and Cognition, 8(4), 336-342. https://doi.org/10.1037/0278-7393.8.4.336

Van Ooijen, A., van Marken Lichtenbelt, W., Van Steenhoven, A., \& Westerterp, K. (2004). Seasonal changes in metabolic and temperature responses to cold air in humans. Physiology \& Behavior, 82(2-3), 545-553. https://doi.org/10.1016/j.physbeh.2004.05.001

Van Strien, T., Cebolla, A., Etchemendy, E., Gutierrez-Maldonado, J., Ferrer-Garcia, M., Botella, C., \& Baños, R. (2013). Emotional eating and food intake after sadness and joy. Appetite, 66, 20-25. https://doi.org/10.1016/j.appet.2013.02.016

Viechtbauer, W. (2010). Conducting meta-analyses in $\mathrm{R}$ with the metafor package. Journal of Statistical Software, 36(3), 1-48. https://doi.org/10.18637/jss.v036.i03

Watson, D., Clark, L. A., \& Tellegen, A. (1988). Development and validation of brief measures of positive and negative affect: The PANAS scales. Journal of Personality and Social Psychology, 54(6), 1063-1079. https://doi.org/10.1037//0022-3514.54.6.1063

Wells, N. M., Ashdown, S. P., Davies, E. H., Cowett, F. D., \& Yang, Y. (2007). Environment, design, and obesity: Opportunities for interdisciplinary collaborative research. Environment and Behavior, 39(1), 6-33. https://doi.org/10.1177/0013916506295570 
WHO. (2020). Obesity and overweight.

https://www.who.int/news-room/fact-sheets/detail/obesity-and-overweight

Willett, W., Rockström, J., Loken, B., Springmann, M., Lang, T., Vermeulen, S., Garnett, T., Tilman, D., DeClerck, F., Wood, A., et al. (2019). Food in the Anthropocene: the EAT-Lancet Commission on healthy diets from sustainable food systems. The Lancet, 393(10170), 447-492.

https://doi.org/10.1016/S0140-6736(18)31788-4

Wisdom, J., Downs, J. S., \& Loewenstein, G. (2010). Promoting healthy choices: Information versus convenience. American Economic Journal: Applied Economics, 2(2), 164-78. https://doi.org/10.1257/app.2.2.164

Wynes, S., \& Nicholas, K. A. (2017). The climate mitigation gap: Education and government recommendations miss the most effective individual actions. Environmental Research Letters, 12(7), 074024. https://doi.org/10.1088/1748-9326/aa7541 


\section{Supplementary online materials}

\section{Pretest}

Various affective states - predominantly negative emotions - can influence food preferences and induce people to favor high-calorie products (Macht, 2008; Van Strien et al., 2013). Therefore, we conducted a pretest to rule out this potential confound and ensure that both experimental videos yielded similar levels of anxiety as well as positive and negative affect.

\section{Method}

Participants. We recruited 140 U.S. participants on Prolific Academic (68 females, $M_{\text {age }}=34.98$ years, $\left.S D=12.80\right)$ to take part in a pretest in exchange for $£ 0.50$.

Procedure. After accepting an informed consent form, participants were randomly assigned to one of the two conditions. They watched either a video showing a forest walk in the winter or in the summer. Both videos lasted 50 seconds. No humans or animals appeared in any scene. The video entitled "Summer forest walk" showed trees covered with leaves and other vegetation typical for the summer. The video entitled "Winter forest walk" showed trees and vegetation covered by snow, typical for the winter.

After watching their assigned video, participants filled out the six-item short-form of the Spielberger State-Trait Anxiety Inventory $(\alpha=.85)$, with responses ranging from 1 $=$ Not at all to $4=$ Very much (Marteau \& Bekker, 1992). We also measured positive $(\alpha$ $=.92)$ and negative $(\alpha=.93)$ affect elicited by the videos using the short version of Positive and Negative Affect Schedule (Watson et al., 1988). The positive and negative affect scales consisted of 10 items each, and were anchored at $1=$ very slightly or not at all, and $5=$ extremely. The pretest concluded with participants providing demographic details.

\section{Results and discussion}

Anxiety. An independent samples $t$-test on the anxiety measure index revealed that the videos elicited similar levels of state anxiety $\left(M_{\text {winter }}=1.89, S D=0.72 ; M_{\text {summer }}\right.$ $=1.97, S D=0.62), t(138)=0.61, p=.542, d=0.10$. 
Positive and negative affect. A comparable analysis performed on the positive affect index indicated no significant differences between conditions $\left(M_{\text {winter }}=2.73, S D=\right.$ $\left.0.83 ; M_{\text {summer }}=2.95, S D=1.00\right), t(138)=1.44, p=.153, d=0.25$. Likewise, comparing negative affect across conditions revealed no differences between them $\left(M_{\text {winter }}=1.53, S D\right.$ $\left.=0.68 ; M_{\text {summer }}=1.61, S D=0.82\right), t(138)=0.62, p=.537, d=0.11$.

Discussion. Results from the pretest provide evidence for the adequacy of our stimuli - we found no significant differences between conditions in anxiety, positive, or negative affect. Therefore, the potential confounds associated with affective states are unlikely to act as the main drivers of the results in our subsequent main studies.

\section{The total number of completed words}

Study 1a. An independent samples $t$-test on the sum of the total number of words completed revealed a marginally significant difference between conditions $\left(M_{\text {winter }}=\right.$ $\left.8.41, S D=2.30 ; M_{\text {summer }}=9.09, S D=1.61\right), t(104)=1.78, p=.078, d=0.35$, indicating that participants exposed to winter cues created fewer words than those exposed to summer cues.

Study 1b. An independent samples $t$-test with the sum of the total number of correct words completed as the dependent variable revealed no significant difference between conditions $\left(M_{\text {winter }}=9.15, S D=1.91 ; M_{\text {summer }}=8.70, S D=2.44\right), t(103)=$ $-1.00, p=.319, d=0.20$. 


\section{Supplementary tables with full model outputs across Studies 2a-2c}

In the main text, we report coefficients multiplied by 100 for readability. Below, we report raw coefficients, that is, before multiplication and additional results that were not reported in the main text for brevity.

Table S1: Study 2a primary hypothesis test results

\begin{tabular}{lc}
\hline & Preference \\
\hline Intercept & -0.02086 \\
& {$[-0.13984,0.09812]$} \\
Condition (winter) & -0.07863 \\
& {$[-0.21812,0.06085]$} \\
Calories & 0.00010 \\
& {$[-0.00007,0.00027]$} \\
Condition (winter) $\times$ Calories & $0.00020^{*}$ \\
& {$[-0.00001,0.00040]$} \\
\hline & ${ }^{*} \mathrm{p}<0.1 ;{ }^{* *} \mathrm{p}<0.05 ;{ }^{* * *} \mathrm{p}<0.01$ \\
Note: & Brackets show $95 \%$ CIs
\end{tabular}


Table S2: Study 2a secondary hypothesis test results

\begin{tabular}{|c|c|}
\hline & Preference \\
\hline \multirow[t]{2}{*}{ Intercept } & $-0.14072^{*}$ \\
\hline & {$[-0.30287,0.02144]$} \\
\hline \multirow[t]{2}{*}{ Condition (winter) } & 0.00560 \\
\hline & {$[-0.19491,0.20611]$} \\
\hline \multirow[t]{2}{*}{ Calories } & $0.00041^{* * *}$ \\
\hline & {$[0.00018,0.00064]$} \\
\hline \multirow[t]{2}{*}{ Sex (woman) } & $0.24809^{* *}$ \\
\hline & {$[0.04874,0.44745]$} \\
\hline \multirow[t]{2}{*}{ Condition (winter) $\times$ Calories } & -0.00012 \\
\hline & {$[-0.00040,0.00017]$} \\
\hline \multirow[t]{2}{*}{ Condition (winter) $\times$ Sex (woman) } & -0.16464 \\
\hline & {$[-0.44661,0.11732]$} \\
\hline \multirow[t]{2}{*}{ Calories $\times$ Sex (woman) } & $-0.00066^{* * *}$ \\
\hline & {$[-0.00096,-0.00036]$} \\
\hline \multirow[t]{2}{*}{ Condition $($ winter $) \times$ Calories $\times$ Sex $($ woman $)$} & $0.00065^{* * *}$ \\
\hline & {$[0.00024,0.00107]$} \\
\hline
\end{tabular}

Note:

${ }^{*} \mathrm{p}<0.1 ;{ }^{* *} \mathrm{p}<0.05 ;{ }^{* * *} \mathrm{p}<0.01$

Brackets show 95\% CIs 
Table S3: Study 26 primary hypothesis test results

\begin{tabular}{lc}
\hline & Preference \\
\hline Intercept & $0.12099^{* *}$ \\
& {$[0.01219,0.22978]$} \\
Condition (winter) & $-0.23458^{* * *}$ \\
& {$[-0.39916,-0.06999]$} \\
Calories & 0.00003 \\
& {$[-0.00010,0.00017]$} \\
Condition (winter) $\times$ Calories & $0.00042^{* * *}$ \\
& {$[0.00020,0.00065]$} \\
\hline Note: & ${ }^{*} \mathrm{p}<0.1 ;{ }^{* *} \mathrm{p}<0.05 ;{ }^{* * *} \mathrm{p}<0.01$ \\
& Brackets show $95 \%$ CIs
\end{tabular}


Table S4: Study $2 b$ secondary hypothesis test results

\begin{tabular}{|c|c|}
\hline & Preference \\
\hline \multirow[t]{2}{*}{ Intercept } & -0.07249 \\
\hline & {$[-0.23692,0.09195]$} \\
\hline \multirow[t]{2}{*}{ Condition (winter) } & -0.08337 \\
\hline & {$[-0.33160,0.16486]$} \\
\hline \multirow[t]{2}{*}{ Calories } & $0.00047^{* * *}$ \\
\hline & {$[0.00026,0.00067]$} \\
\hline \multirow[t]{2}{*}{ Sex (woman) } & $0.29626^{* * *}$ \\
\hline & {$[0.11476,0.47776]$} \\
\hline \multirow[t]{2}{*}{ Condition $($ winter $) \times$ Calories } & $0.00030^{*}$ \\
\hline & {$[-0.00004,0.00063]$} \\
\hline \multirow[t]{2}{*}{ Condition (winter) $\times$ Sex (woman) } & -0.18747 \\
\hline & {$[-0.52204,0.14711]$} \\
\hline \multirow[t]{2}{*}{ Calories × Sex (woman) } & $-0.00064^{* * *}$ \\
\hline & {$[-0.00088,-0.00041]$} \\
\hline \multirow[t]{2}{*}{ Condition $($ winter $) \times$ Calories $\times$ Sex $($ woman $)$} & -0.00002 \\
\hline & {$[-0.00048,0.00043]$} \\
\hline
\end{tabular}

Note:

${ }^{*} \mathrm{p}<0.1 ;{ }^{* *} \mathrm{p}<0.05 ;{ }^{* * *} \mathrm{p}<0.01$

Brackets show 95\% CIs 
Table S5: Study 2c primary hypothesis test results

\begin{tabular}{lc}
\hline & Preference \\
\hline Intercept & 0.03408 \\
& {$[-0.04613,0.11429]$} \\
Condition (winter) & $0.07027^{*}$ \\
& {$[-0.00204,0.14258]$} \\
Calories & $0.00034^{* * *}$ \\
& {$[0.00026,0.00043]$} \\
Condition (winter) $\times$ Calories & -0.00008 \\
& {$[-0.00018,0.00002]$} \\
\hline Note: & ${ }^{*} \mathrm{p}<0.1 ;{ }^{* *} \mathrm{p}<0.05 ;{ }^{* * *} \mathrm{p}<0.01$ \\
& Brackets show $95 \%$ CIs
\end{tabular}




\section{Table 1}

Table S6: Study 2c secondary hypothesis test results

\begin{tabular}{|c|c|}
\hline & Preference \\
\hline \multirow[t]{2}{*}{ Intercept } & -0.03283 \\
\hline & {$[-0.12620,0.06054]$} \\
\hline \multirow[t]{2}{*}{ Condition (winter) } & $0.12633^{* *}$ \\
\hline & {$[0.02513,0.22753]$} \\
\hline \multirow[t]{2}{*}{ Calories } & $0.00057^{* * *}$ \\
\hline & {$[0.00047,0.00068]$} \\
\hline \multirow[t]{2}{*}{ Sex (woman) } & $0.15178^{* * *}$ \\
\hline & {$[0.05053,0.25304]$} \\
\hline \multirow[t]{2}{*}{ Condition $($ winter $) \times$ Calories } & $-0.00024^{* * *}$ \\
\hline & {$[-0.00038,-0.00010]$} \\
\hline \multirow[t]{2}{*}{ Condition (winter) $\times$ Sex (woman) } & $-0.12720^{*}$ \\
\hline & {$[-0.27154,0.01714]$} \\
\hline \multirow[t]{2}{*}{ Calories × Sex (woman) } & $-0.00049^{* * *}$ \\
\hline & {$[-0.00063,-0.00035]$} \\
\hline \multirow[t]{2}{*}{ Condition $($ winter $) \times$ Calories $\times$ Sex $($ woman $)$} & $0.00035^{* * *}$ \\
\hline & {$[0.00015,0.00054]$} \\
\hline
\end{tabular}

Note:

${ }^{*} \mathrm{p}<0.1 ;{ }^{* *} \mathrm{p}<0.05 ;{ }^{* * *} \mathrm{p}<0.01$

Brackets show 95\% CIs 
Figure S1: Video stimuli used across Studies 2a-2c

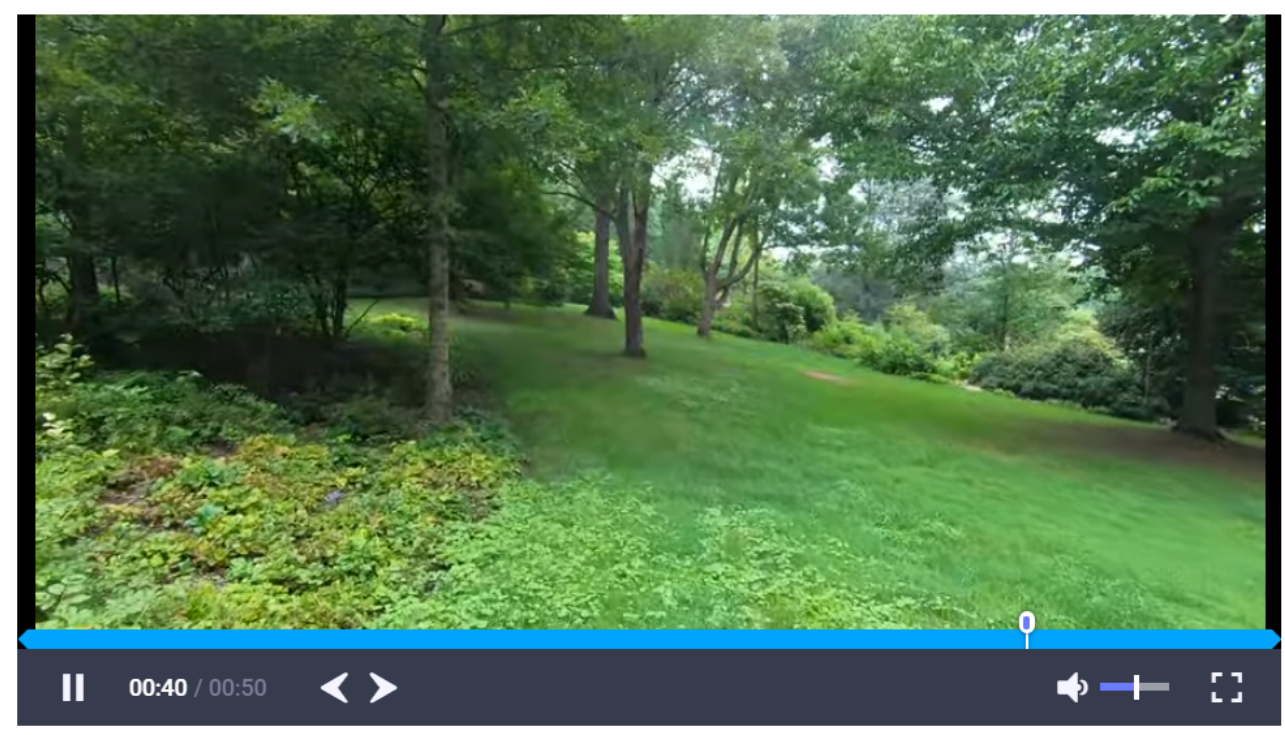

Click this button to continue

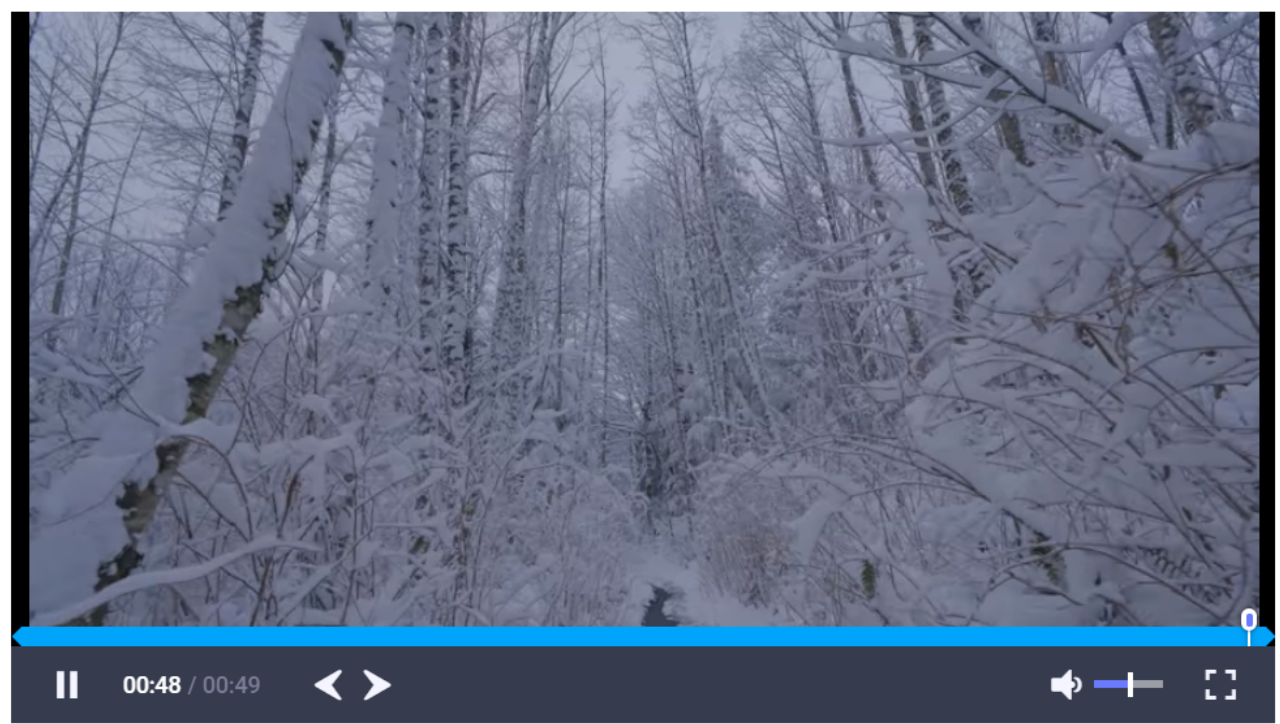


Figure S2: Sample tasks used across Studies 1a-1b

\section{Complete words using the given letters}

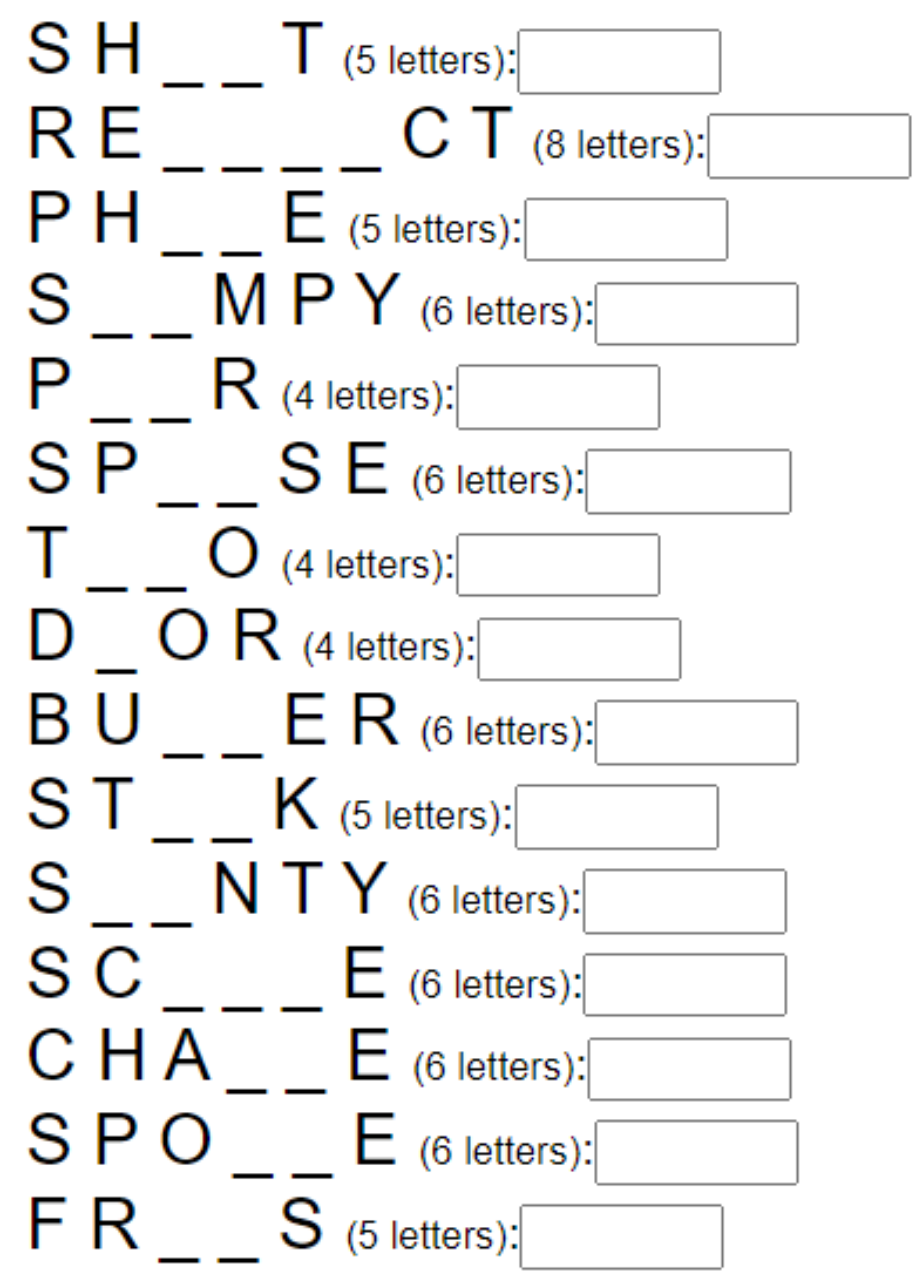


Figure S3: Sample tasks used across Studies 2a-2c

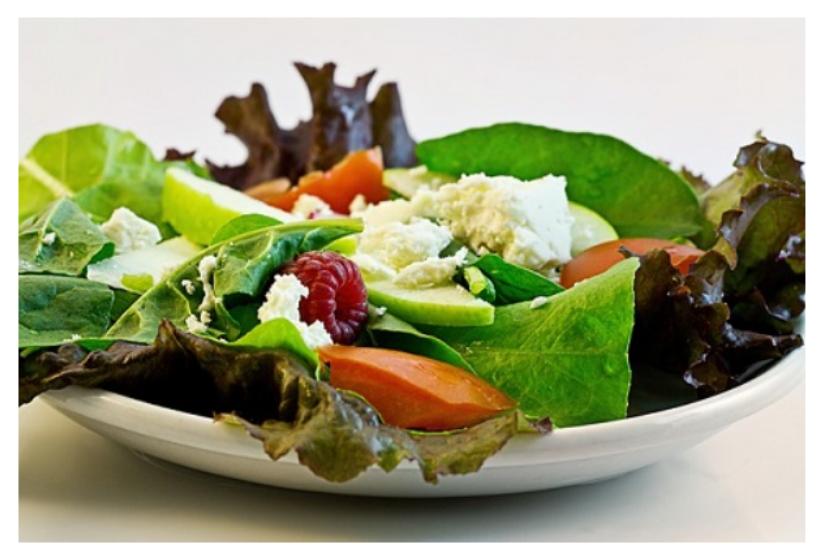

Would you eat this food now?

Click this button to continue

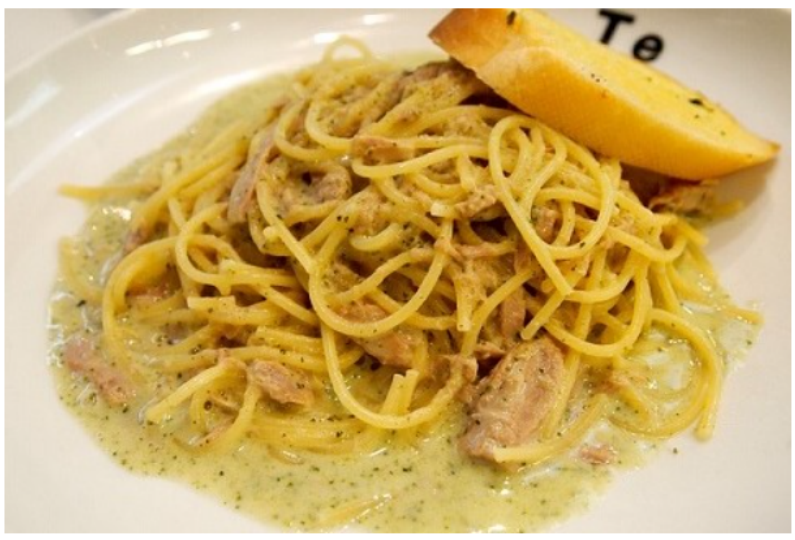

How many calories does this food contain? (the serving you see)

Click this button to continue 